\title{
Gender differences in pain prevalence, characteristics, assessment and treatment in internal medicine patients: a post-hoc analysis of the FADOI-DOMINO study
}

\author{
Giuseppe Civardi, ${ }^{1}$ Patrizia Mordenti, ${ }^{2}$ Gualberto Gussoni, ${ }^{3}$ Cecilia Politi, ${ }^{4}$ Pietro Seghini, ${ }^{2}$ Maria Cristina Pasquini, ${ }^{5}$ \\ Stefania Marengo, ${ }^{6}$ Pietro De Bastiani, ${ }^{7}$ Antonella Valerio, ${ }^{3}$ Andrea Fontanella ${ }^{8}$ on behalf of the FADOI-DOMINO \\ Study Group*
}

${ }^{1}$ Long-term Care and Rehabilitation Unit, Casa di Cura S. Antonino, Piacenza; ${ }^{2}$ Oncology Department, AUSL di Piacenza; ${ }^{3}$ Clinical Research Department, FADOI Foundation, Milano; ${ }^{4}$ Internal Medicine Unit, City Hospital, Isernia; ${ }^{5}$ Oncology Unit, Hospital Maggiore, Crema (CR); ${ }^{6}$ Internal Medicine Department, Hospital Mauriziano, Torino; ${ }^{7}$ Internal Medicine Unit, Hospital of Oderzo, Treviso; ${ }^{8}$ Internal Medicine Department, Hospital Fatebenefratelli, Napoli, Italy

\begin{abstract}
Conflicting results come from epidemiological studies on the correlations between gender and pain in hospitalized patients. No specific data are reported in patients admitted to Internal Medicine Units (IMUs). Post-hoc analysis of the FADOI-DOMINO study, performed in 26 IMUs in Italy, with two cross-sectional surveys interspersed with an educational program. The 5200 medical charts of the FADOI-DOMINO study were re-analyzed. The following sex differences were highlighted: i) a greater pain prevalence was evidenced in women in the Pre-phase; ii) among patients with chronic pain, anxiety and depression were significantly more present in women compared with men; iii) oncologic pain was more prevalent in men; in a specular way, nononcologic pain showed a greater prevalence in women in both phases; iv) strong opioids therapy was higher for men. Some sex differences in pain seem to exist in IMUs, although less evident if compared with those previously reported in other settings. A more careful assessment of coexisting conditions such as anxiety, depression or cognitive impairment can result in a better management of these problems.

*List of the Members of the FADOI-DOMINO Study Group M. Alessandri, O. Panichi (Grosseto); G. Arcelli, P.V. Paoletti
\end{abstract} (Città di Castello - PG); P. Bordin, L. Perale (San Daniele del Friuli - UD); A.L. Brucato, S. Ghidoni (Bergamo); G. Brunelleschi, C. Andreucci (Lucca); M. Campanini, F. Bobbio (Novara); R. Cavaliere, C. Norbiato, S. Marengo, A. Briozzo, S. Terzolo, (Torino); R. Centurioni, C. Quattrini (Civitanova Marche - AN); G. Civardi (Fiorenzuola d'Arda - PC); P. De Bastiani (Motta di Livenza -TV); M. Dore, M.R. Marcialis (Rivoli - TO); G. Fiorini, M.C. Pasquini (Crema - CR); A. Fontanella (Napoli); L. Mazzuca, M. Ferraro, F. Iaquinta (Acri - CS); A. Mazzone, M. Rondena (Legnano - MI); F. Miserocchi (Valdagno - VI); A. Morettini, A. Petrioli (Firenze); R. Pastorelli, M. Pellegrinotti (Colleferro - RM); A. Perugini, F. Serra, A. Bini (Roma); A. Puleo, S. La Carruba (Palermo); M. Romano, F. Paternò Raddusa, (Catania); D. Ruggero, C.D. Ciannamea, S. Sabatino (Molfetta - BA); R. Tassara, A. Fiorucci, M. Bella (Savona); V. Tucci, R. Costa, M. Nocera (Crotone); F. Tremolada, F. Beccaro, G. Fabris (Padova); G. Uomo, F. Gallucci (Napoli).

Received for publication: 26 February 2018.

Revision received: 2 July 2018.

Accepted for publication: 16 July 2018.

This work is licensed under a Creative Commons Attribution NonCommercial 4.0 License (CC BY-NC 4.0).

CCopyright G. Civardi et al., 2018

Licensee PAGEPress, Italy

Italian Journal of Medicine 2018; 12:213-218

doi:10.4081/itjm.2018.1008

\section{Introduction}

Researches on the possible physiopathological, clinical and epidemiological correlations between gender and pain have increased exponentially in recent years. ${ }^{1}$ The topics evaluated are varying, such as preclinical studies on mechanisms responsible for sex differences in pain, human laboratory researches on sex differences in pain perception and endogenous pain modulation, clinical and epidemiological studies about sex differences in pain prevalence and in response to pain treatments. Population-based studies consistently demonstrate greater pain prevalence among women compared with men. ${ }^{1}$ At the same time, the general prevalence of several common chronic pain conditions appears greater in women than in men, namely fibromyalgia, migraine and tension-type headache, temporo-mandibular disorders, irritable bowel syndrome and interstitial cystitis. ${ }^{1,2}$ On the other hand, conflicting results come from epidemiological 
studies in hospitalized patients. Costantini et al. ${ }^{3}$ and Trentin et al. ${ }^{4}$ reported pain as slightly more frequent in women than in men: on the other hand, a more recent paper of Visentin et al. ${ }^{5}$ reported no difference in the prevalence of pain. Moreover, no specific data on patient admitted to Internal Medicine wards are reported in these papers. Finally, we found no data on gender difference in pain treatment before and after educational interventions.

With respect to experimentally-induced pain, previous qualitative and quantitative researches have usually concluded that women display greater sensitivity to multiple pain modalities compared with men, and show greater temporal summation of pain while men present greater conditioned pain modulation. ${ }^{2,6,7}$ However, a more recent review reveals that there are inconsistent data to demonstrate a correlation between sex and pain sensitivity. ${ }^{8}$ Sex differences in response to pain treatment are also described; in particular, a recent meta-analysis concluded that women exhibit greater analgesia in response to mixed action opioids at least in clinical studies. ${ }^{9}$ Moreover, data from other studies suggest that there could be also sex differences in response to non-pharmacologic treatment. ${ }^{10,11}$ Furthermore, another matter of debate remains the underlying mechanisms of such a disparity, with the interaction of biological, psychological and sociocultural factors being suggested as the most possible responsible. ${ }^{6,12,13}$ An intriguing conclusion could be that really, the pain experience of women and men does not differ in a phenomenological sense but rather, they could describe their experiences in different ways. ${ }^{14}$

In this paper we report the results of a post-hoc analysis of the previously published FADOIDOMINO study, ${ }^{15}$ in which data on pain assessment and treatment in a large population of patients admitted to 26 Internal Medicine wards in Italy were analyzed before and after an on-site educational intervention that involved both physicians and nurses. The aim of our analysis was to re-evaluate the findings we obtained in this population of patients, in order to verify a possible correlation between gender and pain prevalence, association with depression and cognitive impairment, clinical assessment and treatment.

\section{Materials and Methods}

We retrospectively analyzed the data of the FADOI-DOMINO study ${ }^{15}$ that was performed in 26 Internal Medicine Units in Italy, with two crosssectional surveys (Pre-phase and Post-phase) interspersed with an educational program. In the Prephase each center reviewed the hospital charts of the last one hundred consecutive patients hospitalized for any cause. An educational program was conducted in each center by means of the outreach visit, a face-toface meeting between health personnel and a trained external expert. Six months after, each center repeated the data collection (Post-phase), specular to the prephase. In our post-hoc analysis of both phases, we focused our attention on sex differences in reported incidence of pain, reporting of pain intensity monitoring, presence of depression or cognitive impairment, registration in the clinical records of quali-quantitative definition of pain and duration, oncologic or non-oncologic pain, use of strong opioids and opioids adverse effects. As for statistical analysis, descriptive statistics refer to all included patients. For continuous variables, mean and standard deviation were calculated. For each discrete variable, the percentage (prevalence) was calculated as the number of cases in each category, in relation to all cases with non-missing values of that variable. In general, statistical comparisons of Pre-phase versus Post-phase and comparison of gender in each phase were performed with the Chi-square test; a P value less than 0.05 was deemed as statistically significant. All statistical analyses were generated with the use of standard procedures of SAS software, version 9.2 (SAS Institute, Cary, NC, USA).

\section{Results}

All the 5200 medical charts of the FADOIDOMINO study were re-analyzed: the characteristics of the population were described elsewhere. ${ }^{15}$ In particular, $70.8 \%$ of our patients were 70 years or older and $61.2 \%$ among them showed three or more medical concomitant conditions.

The data on gender, prevalence of pain, reporting of pain intensity monitoring, prevalence of depression and cognitive impairment are summarized in Table 1. A greater pain prevalence was evidenced in women but only in the Pre-phase of the study $(37.4 \% v s$ $32.6 \%, \mathrm{P}<0.001$ ); interestingly, after the educational program no sex differences appeared in pain reporting $(37.7 \%$ vs $37.2 \%, \mathrm{P}=0.73)$. When we analyzed the prevalence of pain in female groups according to the geographical distribution (North $v s$ Centre $v s$ South Italy), we noted a gradient of prevalence among the three different areas of Italy (prevalence of pain: $47.5 \%, 34.2 \%$ and $24.8 \%$ respectively). In our study we did not collect data on ethnicity, social conditions and cultural level of patients. The registration in the clinical records of pain intensity monitoring during the post educational phase was significantly higher than the pre-educational phase $(\mathrm{P}<0.001)$, but no sex differences were evident in the two phases (pre-phase: $47.3 \%$ vs $48.0 \%$, post-phase: $77.1 \%$ vs $77.7 \%$ : $\mathrm{P}=\mathrm{ns}$ ). When evaluating a possible correlation with common chronic pain conditions, a relationship was found for 
anxiety and depression in women compared with men in both phases of the study $(26.7 \%$ vs $22 \%, \mathrm{P}<0.001$ in Pre-phase; $28 \%$ vs 16.5\%, $\mathrm{P}<0.001$ in Post-phase); for cognitive impairment a difference appeared in women compared with men only in the Pre-phase (20.3\% vs $14.3 \%, \mathrm{P}<0.001)$.

In Table 2 the data on the presence in the clinical records of clinical characteristics and duration of pain, prevalence of cancer and non-cancer pain, strong opioids therapy and side effects are reported. In the post educational phase, the percentages of patients with assessment of the characteristics of pain was significantly greater with respect to the pre-educational phase $(\mathrm{P}<0.001)$, but without sex differences in both phases (pre-phase: $61.7 \%$ vs $63.3 \%$; post-phase: $75.7 \%$ vs $75 \%$ : $\mathrm{P}=\mathrm{ns}$ ). When stratifying patients for oncologic and non-oncologic pain, our analysis revealed a greater prevalence of the first in men in both phases of the study (8.8\% vs 5.7\%, $\mathrm{P}<0.001$ in Pre-phase; $10.4 \%$ vs $6.7 \%$, $\mathrm{P}<0.001$ in Post-phase); in a specular way, nononcologic pain showed a greater prevalence in women in both phases (29.6\% vs 21.5\%, $\mathrm{P}<0.001$ in Pre-phase; $29.4 \%$ vs $24.8 \%, \mathrm{P}<0.001$ in Post-phase).

The prevalence of strong opioids therapy was higher for men with respect to women for all phases of the study, but it reached statistical significance only in the Post-phase ( $8.8 \%$ vs $7.6 \%$ in Pre-phase, $\mathrm{P}=0.11$; $15.3 \%$ vs $12.9 \%, \mathrm{P}=0.012$ in Post-phase). Finally, no sex differences were evidenced for opioids-induced adverse effects, having constipation, nausea/vomiting and drowsiness the same incidence in men as compared with women.

\section{Discussion}

Pain can be viewed as a leading health problem all over the world since the Institute of Medicine indicates for its management an annual economic burden of about $\$ 700$ billion in the United States. ${ }^{16}$ While acute pain is one of the most important reasons for admission to emergency care, ${ }^{17}$ chronic pain leads to diminished quality of life, physical disability and is a serious risk factor for suicide. ${ }^{14} \mathrm{~A}$ broad range of variables determine the different pain responses from an individual to an another. Sex turns out to be a critical factor in modulating the experience of pain with a growing evidence from research demonstrating that the two sexes experience pain in a different manner as well as they respond differently to specific classes of analgesic drugs. At the same time, numerous biopsychosocial mechanisms are hypothesized to be

Table 1. Prevalence of pain, pain intensity evaluation and some associated conditions, in a population of 5200 patients admitted to Internal Medicine wards according to gender distribution and phases of the DOMINO study. Data are expressed as percentage. Statistical comparisons are between genders within study phases.

\begin{tabular}{|c|c|c|c|c|c|c|c|c|c|c|}
\hline & \multicolumn{2}{|c|}{$\begin{array}{c}\text { Population } \\
\text { (5200 pts) } \\
\text { (Pre-phase: } 2,600 \text { ) } \\
\text { (Post-phase: } 2600 \text { ) }\end{array}$} & \multicolumn{2}{|c|}{$\begin{array}{l}\text { Patients with } \\
\text { pain }\end{array}$} & \multicolumn{2}{|c|}{$\begin{array}{l}\text { Pain intensity } \\
\text { reported } \\
\text { (within patients } \\
\text { with pain) }\end{array}$} & \multicolumn{2}{|c|}{$\begin{array}{c}\text { Presence of } \\
\text { depression } \\
\text { (within patients } \\
\text { with pain) }\end{array}$} & \multicolumn{2}{|c|}{$\begin{array}{c}\text { Presence of } \\
\text { cognitive impairment } \\
\text { (within patients } \\
\text { with pain) }\end{array}$} \\
\hline & Male & Female & Male & Female & Male & Female & Male & Female & Male & Female \\
\hline Pre-phase & $48.6^{\circ}$ & 51.4 & $32.6^{*}$ & 37.4 & 47.3 & 48.0 & 17.5 & 18.8 & $22.0^{*}$ & 26.7 \\
\hline Post-phase & 49.3 & 50.7 & 37.2 & 37.7 & 77.1 & 77.7 & $14.3 *$ & 20.3 & $16.5^{*}$ & 28.0 \\
\hline $\begin{array}{l}\text { Statistical } \\
\text { significance }\end{array}$ & \multicolumn{2}{|c|}{$\left({ }^{\circ}\right)=\mathrm{P}<0.05$} & \multicolumn{4}{|c|}{$(*)=\mathrm{P}<0.001$} & \multicolumn{2}{|c|}{$(*)=\mathrm{P}<0.001$} & \multicolumn{2}{|c|}{$(*)=\mathrm{P}<0.001$} \\
\hline
\end{tabular}

Table 2. Prevalence of some clinical and therapeutic findings, in a population of patients with pain admitted to Internal Medicine wards according to gender distribution and phases of the DOMINO study. Data are expressed as percentage. Statistical comparisons are between genders within study phases.

\begin{tabular}{|c|c|c|c|c|c|c|c|c|c|c|}
\hline & \multicolumn{2}{|c|}{$\begin{array}{l}\text { Clinical pain } \\
\text { characteristics } \\
\text { reported }\end{array}$} & \multicolumn{2}{|c|}{$\begin{array}{l}\text { Percentage of } \\
\text { non-cancer pain }\end{array}$} & \multicolumn{2}{|c|}{$\begin{array}{l}\text { Percentage of } \\
\text { cancer pain }\end{array}$} & \multicolumn{2}{|c|}{$\begin{array}{l}\text { Strong opioid } \\
\text { therapy }\end{array}$} & \multicolumn{2}{|c|}{$\begin{array}{l}\text { Percentage of } \\
\text { strong opioid-related } \\
\text { side effects }\end{array}$} \\
\hline & Male & Female & Male & Female & Male & Female & Male & Female & Male & Female \\
\hline Pre-phase & 61.7 & 63.3 & $21.5^{*}$ & 29.6 & $8.8^{*}$ & 5.7 & 8.8 & 7.6 & 12.5 & 12.2 \\
\hline Post-phase & 75.7 & 75 & $24.1 *$ & 29.4 & $10.4^{*}$ & 6.7 & $15.3^{*}$ & 12.9 & 11.7 & 11.9 \\
\hline $\begin{array}{l}\text { Statistical } \\
\text { significance }\end{array}$ & & & \multicolumn{2}{|c|}{$(*)=\mathrm{P}<0.001$} & \multicolumn{2}{|c|}{$(*)=\mathrm{P}<0.001$} & \multicolumn{2}{|c|}{$(*)=\mathrm{P}<0.001$} & & \\
\hline
\end{tabular}


responsible for sex differences both in acute and chronic pain, such as different influence of sex hormones on central and peripheral nervous system, ${ }^{13,18}$ gender differences in stress-induced hyperalgesia and analgesia, ${ }^{13}$ psychological response to stress and pain, ${ }^{13}$ endogenous opioid function, ${ }^{19}$ and pain reporting. ${ }^{18}$ Taken together, the findings from epidemiological and clinical studies clearly demonstrate that women have a substantially higher risk for many common pain conditions. With respect to pain intensity, results are less consistent and likely influenced by multiple methodological factors, including selection biases in studies and the potential for sex differences in the effects of pain treatments. On the other hand, no such data are available in the present literature on series of patients admitted to Internal Medicine wards, that are frequently elderly, frail and with heavy multimorbidity burden. Our results agree only partially with data from literature. In fact, in our population we reported no clear gender differences in pain prevalence, with only a slightly greater prevalence for pain in women but only in the Pre-phase of our study. This can be due to the high prevalence of multimorbidity in our population: as reported by Patel et al., ${ }^{20}$ the increasing number of associated medical conditions plays a major role on pain prevalence in the elderly. The slight difference between the two phases could be explained with the increasing attention of health care providers in pain reporting, obtained after the educational intervention. In relation to the regional distribution of the prevalence of pain, our data are inconclusive and potentially misleading. The lack of data to correlate regional differences with ethnicity, social and cultural status of the study population, does not allow to draw any conclusion on this issue.

In our study we found a greater prevalence of depression among women in both study phases, and these data agree with available literature. Cognitive impairment was more frequently reported in women only in the Pre-phase. This last finding could be due to the influence related to the educational training, as previously said.

When evaluating possible mechanisms implicated in sex differences in pain, those like anxiety, depression, attentional processes, pain-coping strategies and catastrophizing appeared associated with the experience and report of pain, and all have been shown to vary as a function of sex. While men usually use behavioral distraction and problemfocused tactics to manage pain, women frequently use coping techniques such as social support, positive selfstatements, emotion-focused strategies, cognitive reinterpretation, attentional processes. ${ }^{6,12}$ Catastrophizing, defined as a negative cognitive and affective response to pain including feelings of helplessness, magnification and ruminative thoughts, is more common in women. Sex differences in catastrophizing have been shown to mediate sex differences in clinical pain in patients with chronic pain. ${ }^{14}$ Some evidence indicates that men demonstrate greater self-efficacy, referred as the belief that one can successfully perform a behavior to achieve a desirable objective. ${ }^{1}$ A lower degree of self-efficacy has been found to be associated with higher levels of pain and physical symptoms. ${ }^{1,21}$ Similarly, depressive symptoms are viewed as predictors of future musculoskeletal disorders such as low back pain; $;{ }^{14}$ on the other hand, positive emotions appear associated with a reduction in pain reporting. ${ }^{14}$ Also, the sociocultural belief about sex role is being addressed as a relevant determinant of pain responses, since pain expression is usually more socially acceptable among women; ${ }^{22}$ moreover, culture-related variability in stereotypical beliefs about pain can play a role in sex differences. ${ }^{23}$

Intriguingly, our study did not reveal sex differences in relation to the quali-quantitative definition of pain (continuous, continuous with exacerbations, breakthrough pain). This was an unexpected observation and we can only speculate that as stated by Paller ${ }^{14}$ the two sexes could also describe their pain experiences in different ways, but both use the same terms when they are requested to better qualify the type of pain. However, it should be pointed out that our patients all suffered from chronic pain, so that we can suppose they had more ability to give a best quali-quantitative definition.

By stratifying the pain by cause, we observed a greater prevalence of oncologic pain in men, while non-oncologic pain was more frequent in women. This could agree with findings from literature showing a higher prevalence of some chronic pain conditions in women relative to men., ${ }^{1,2}$ Furthermore, research findings highlight that estrogen in premenopausal women seems to enhance pain in most chronic diseases while testosterone more probably improves quality of life. ${ }^{14}$

Moreover, this finding well correlates with the evidence of a major use of strong opioids in our male population, since these drugs are more frequently prescribed for cancer pain.

In our experience, opioids-related adverse events were similar in men and women, in particular for nausea/vomiting, constipation and numbness. Once again, this evidence is partially discordant with data from literature suggesting that women experience more toxicity from opioids particularly when referring nausea and vomiting. ${ }^{24,25}$ Nevertheless, in our hospitalized population the pain is more frequently chronic and patients could be accustomed to take opioids and therefore suffer less adverse effects. 
Our study has some limitations: since it was conducted in Internal Medicine Units, it explores almost exclusively chronic pain. So, we cannot draw any conclusion about gender differences in acute pain. Moreover, we do not evaluate the possible interference with the healthcare providers features. In fact, clinical research supports the hypothesis that pain reporting may vary as a function of the sex of healthcare provider; this observation pinpoints the importance of the interpersonal context of verbal pain reporting. ${ }^{14}$ Furthermore, other studies reveal sex differences also in the diagnosis and treatment options that healthcare providers predispose for patients that complain pain. ${ }^{14,26,27}$

Finally, our data were not stratified with respect to biological, psychological, sociocultural factors as well as for demographic provenience since patients were of every race and religion, social and cultural level and resident both in urban and suburban areas.

On the other hand, our study has some strengths: we report data on gender differences on pain in a wide population of frail, elderly patients with heavy comorbidity, admitted to Internal Medicine wards, a setting for which such data were not previously available. Moreover, this is a multicenter study and this feature strengthens our results and the possibility to extend them to a wider population.

Furthermore, the Pre-phase and Post-phase were interspersed by an educational program that allowed us to potentiate the skills of healthcare providers in pain identification, definition and reporting as well as in pain management and treatment.

In conclusion, to our knowledge, our work is the first that evaluates in detail the prevalence and characteristics of pain in a population of patients admitted to Internal Medicine Departments. Starting from our experience we can conclude that some sex differences in pain could really exist in our population of patients admitted to Internal Medicine wards, although less evident as previously reported in other settings. Probably, sex differences in pain prevalence could be reduced with educational programs aimed at improving the skills of healthcare providers in pain identification and reporting. In our study anxiety, depression and partly also cognitive impairment were more frequently associated with chronic pain conditions in women than in men. As a perspective, a major attention for coexisting common conditions such as anxiety, depression or cognitive impairment can result in a better management of these problems and in turn of pain. In our experience sex differences exist for oncologic and nononcologic pain, being the first more prevalent in men and the second in women. Consequently, sex differences exist in the prescription of strong opioids that is less frequent for women.

\section{References}

1. Bartley EJ, Fillingim RB. Sex differences in pain: a brief review of clinical and experimental findings. $\mathrm{Br} \mathrm{J}$ Anaesthesia 2013;111:52-8.

2. Mogil JS. Sex differences in pain and pain inhibition: multiple explanations of a controversial phenomenon. Nat Rev Neurosci 2012;13:859-66.

3. Costantini M, Viterbori P, Fiego G. Prevalence of pain in Italian hospital: results of a regional cross-sectional study. J Pain Symptom Manag 2002;23:221-30.

4. Trentin L, Visentin M, De Marco R, Zanolin E. Prevalence of pain in a public hospital: correlation between patients and caregivers. J Headache Pain 2001;2:73-8.

5. Visentin M, Zanolin E, Trentin L, et al. Prevalence and treatment of pain in adults admitted to Italian hospitals. Eur J Pain 2005;9:61-7.

6. Fillingim RB, King CD, Ribeiro-Dasilva MC, et al. Sex, gender, and pain: a review of recent clinical and experimental findings. J Pain 2009;10:447-85.

7. Popescu A, LeResche L, Truelove EL, Drangsholt MT. Gender differences in pain modulation by diffuse noxious inhibitory controls: a systematic review. Pain 2010;150:309-18.

8. Racine M, Tousignant-Laflamme Y, Kloda LA, et al. A systematic literature review of 10 years of research on sex/gender and experimental pain perception-part 1: are there really differences between women and men? Pain 2012;153:602-18.

9. Niesters M, Dahan A, Kest B, et al. Do sex differences exist in opioid analgesia? A systematic review and metaanalysis of human experimental and clinical studies. Pain 2010;151:61-8.

10. Keogh E, McCracken LM, Eccleston C. Do men and women differ in their response to interdisciplinary chronic pain management? Pain 2005;114:37-46.

11. Pieh C, Altmeppen J, Neumeier S, et al. Gender differences in outcomes of a multimodal pain management program. Pain 2012;153:197-202.

12. Racine M, Tousignant-Laflamme Y, Kloda LA, et al. A systematic literature review of 10 years of research on sex/gender and pain perception-part 2: do biopsychosocial factors alter pain sensitivity differently in women and men? Pain 2012;153:619-35.

13. Greenspan JD, Craft RM, LeResche L, et al. Studying sex and gender differences in pain and analgesia: a consensus report. Pain 2007;132:S26-45.

14. Paller CJ, Campbell CM, Edwards RR, Dobs AS. Sexbased differences in pain perception and treatment. Pain Med 2009;10:289-99.

15. Civardi G, Zucco F, Valerio A, et al. Pain management in Internal Medicine and effects of a standardised educational intervention: the FADOI-DOMINO Study. Int J Clin Pract 2015;69:33-40.

16. Institute of Medicine. Relieving pain in America: a blueprint for transforming prevention, care, education, and research. Washington DC: National Academies Press; 2011.

17. Patel R, Biros MH, Moore J, Miner JR. Gender differences in patient-described pain, stress, and anxiety among patients undergoing treatment for painful 
conditions in the Emergency Department. Acad Emerg Med 2014;21:1478-84.

18. LeResche L. Defining gender disparities in pain management. Clin Orthop Relat Res 2011;469:1871-7.

19. Frew AK, Drummond PD. Negative affect, pain and sex: the role of endogenous opioids. Pain 2007;132:S77-85.

20. Patel KV, Guralnik JM, Dansie EJ, Turk DC. Prevalence and impact of pain among older adults in the United States: findings from the 2011 National Health and Aging Trends Study. Pain 2013;154:2649-57.

21. Somers TJ, Kurakula PC, Criscione-Schreiber L, et al. Selfefficacy and pain catastrophizing in systemic lupus erythematosus: relationship to pain, stiffness, fatigue, and psychological distress. Arthritis Care Res 2012;64:1334-40.

22. Robinson ME, Riley JL III, Myers CD, et al. Gender role expectations of pain: relationship to sex differences in pain. J Pain 2001;2:251-7.

23. Defrin R, Shramm L, Eli I. Gender role expectations of pain is associated with pain tolerance limit but not with pain threshold. Pain 2009;145:230-6.

24. Dahan A, Kest B, Waxman AR, Sarton E. Sex-specific responses to opiate: animal and human studies. Anesth Analg 2008;107:83-95.

25. Musey PI, Linnstaedt SD, Platts-Mills TF, et al. Gender differences in acute and chronic pain in the Emergency Department: results of the 2014 Academic Emergency Medicine Consensus Conference Pain Section. Acad Emerg Med 2014;21:1421-30.

26. Hamberg K, Risberg G, Johansson EE, Westman G. Gender bias in physicians' management of neck pain: a study of the answers in a Swedish national examination. J Women Health Gend Based Med 2002;11:653-66.

27. Weisse CS, Sorum PC, Sanders KN, Syat BL. Do gender and race affect decisions about pain management? J Gen Intern Med 2001;16:211-7. 